\title{
Time of day of prednisolone administration in rheumatoid arthritis
}

\author{
I. C. KOWANKO, R. POWNALE, M. S. KNAPP, A. J. SWANNELL, AND \\ P. G. C. MAHONEY
}

From the City Hospital, Hucknall Road, Nottingham NG5 1PB

SUMmaRY Twelve patients with rheumatoid arthritis took low dosage prednisolone, mean $5.6 \mathrm{mg}$ daily, at either $0800 \mathrm{~h}, 1300 \mathrm{~h}$, or $2300 \mathrm{~h}$ in a double-blind within-patient controlled trial. Each patient was studied on each of the 3 regimens to assess control of symptoms and side effects and also to examine circadian rhythms in signs and symptoms. For several days during each drug regimen patients collected urine at each micturition and self-assessed their signs and symptoms. Circadian rhythms of finger joint swelling and of grip strength were determined, and were similar on all regimens, with morning peaks of symptoms and signs. Subjective and objective assessments showed no differences in effectiveness between the 3 times of administration of prednisolone. Urinary excretion patterns were similar to those observed in untreated people. The quantity and circadian pattern of 11-hydroxycorticosteroids excreted were similar to those in healthy patients, providing no evidence of adrenal cortical suppression at the dose levels studied, even when this dose was taken in the evening. A single morning dose of prednisolone appears in many patients to be as effective as a single evening dose or divided doses. It is therefore reasonable to initiate therapy with a morning-only regimen, because adrenopituitary suppression should be minimised.

The symptoms of rheumatoid arthritis are worst in the morning, and treatment is often requested to help with this uncomfortable phase. Prednisolone and

Accepted for publication 2 October 1981.

Correspondence to Dr I. C. Kowanko. other glucocorticoids are often given in the evening for rheumatoid arthritis, either as part of a divided dose regimen or as a single evening dose. Some authors recommend nocturnal-only administration. ${ }^{12}$

The severity of glucocorticoid side effects depends

Table 1 Details of patients

\begin{tabular}{|c|c|c|c|c|c|c|c|}
\hline $\begin{array}{l}\text { Patient } \\
\text { no. }\end{array}$ & $\begin{array}{l}\text { Age } \\
\text { (years) }\end{array}$ & Sex & $\begin{array}{l}\text { Daily dose } \\
\text { prednisolone } \\
\text { during trial } \\
\text { (mg) }\end{array}$ & $\begin{array}{l}\text { Concurrent } \\
\text { medication }\end{array}$ & $\begin{array}{l}\text { Duration } \\
\text { of steroid } \\
\text { therapy } \\
\text { (months) }\end{array}$ & $\begin{array}{l}\text { Maximum } \\
\text { daily dose } \\
\text { prednisolone ever } \\
(\mathrm{mg})\end{array}$ & $\begin{array}{l}\text { Usual } \\
\text { time of } \\
\text { prednisolone } \\
\text { therapy }\end{array}$ \\
\hline 1 & 61 & $\mathbf{M}$ & 5 & $\begin{array}{l}\text { Indomethacin, } \\
\text { paracetamol }\end{array}$ & 34 & 5 & 0800 \\
\hline 2 & 54 & $\mathbf{F}$ & 5 & $\begin{array}{l}\text { Indomethacin, sodium } \\
\text { aurothiomalate }\end{array}$ & 336 & 10 & $\begin{array}{l}0700 \\
2300\end{array}$ \\
\hline 3 & 54 & $\mathrm{~F}$ & 5 & $\begin{array}{l}\text { Aspirin, penicillamine, } \\
\text { indomethacin }\end{array}$ & 48 & 10 & 0800 \\
\hline 4 & 69 & $\mathbf{F}$ & 10 & Aspirin, cyclophosphamide & 12 & 10 & 1000 \\
\hline $5^{*}$ & 45 & $\mathrm{~F}$ & 5 & Ibuprofen, indomethacin & 120 & 15 & 0800 \\
\hline $6+$ & 52 & $\mathbf{M}$ & 5 & $\begin{array}{l}\text { Paracetamol, sodium } \\
\text { aurothiomalate }\end{array}$ & 1 & 5 & 0800 \\
\hline $7 \ddagger$ & 49 & $\mathbf{M}$ & 5 & $\begin{array}{l}\text { Ibuprofen, fenoprofen, } \\
\text { aloxiprin, paracetamol, sodium } \\
\text { aurothiomalate, nitrazepam }\end{array}$ & 18 & $7 \cdot 5$ & 2300 \\
\hline 8 & 48 & $\mathbf{M}$ & 5 & Ibuprofen, indomethacin & 96 & $12 \cdot 5$ & 2100 \\
\hline 9 & 61 & $\mathbf{F}$ & 5 & $\begin{array}{l}\text { Indomethacin, sodium } \\
\text { aurothiomalate }\end{array}$ & 7 & 5 & 1900 \\
\hline 10 & 57 & $\mathrm{~F}$ & 5 & $\begin{array}{l}\text { Paracetamol, benorylate, } \\
\text { penicillamine }\end{array}$ & 24 & 20 & 0900 \\
\hline 11 & 50 & $\mathbf{M}$ & $7 \cdot 5$ & $\begin{array}{l}\text { Flurbiprofen, paracetamol, } \\
\text { penicillamine }\end{array}$ & 264 & 15 & $\begin{array}{l}0900 \\
1300 \\
2300\end{array}$ \\
\hline $\begin{array}{l}12 \\
\text { Mean }\end{array}$ & $\begin{array}{l}59 \\
54 \cdot 9\end{array}$ & $\mathbf{F}$ & $\begin{array}{l}5 \\
5 \cdot 6\end{array}$ & Aloxiprin, nitrazepam & $\begin{array}{r}120 \\
90\end{array}$ & $\begin{array}{l}40 \\
12 \cdot 9\end{array}$ & 0800 \\
\hline
\end{tabular}

* No finger joint size measurements due to numerous subcutaneous nodules over the joints.

+Withdrew while on $1300 \mathrm{~h}$ dosing, after a recurrence of pulmonary oedema, for which diuretics were prescribed.

$\ddagger$ Withdrew while on $1300 \mathrm{~h}$ dosing, of his own accord, with mild chest pains and faintness. 
on the time of day of administration. ${ }^{3}$ Adrenopituitary suppression is maximal when steroids are given at night but minimal or absent with morning administration. ${ }^{4}$ Other side effects, for example nocturia, ${ }^{5}$ may be reduced by morning-only administration. ${ }^{6}$

The logic of giving prednisolone at night to reduce or avoid symptoms which are troublesome in the morning is clear, but side effects might be expected to

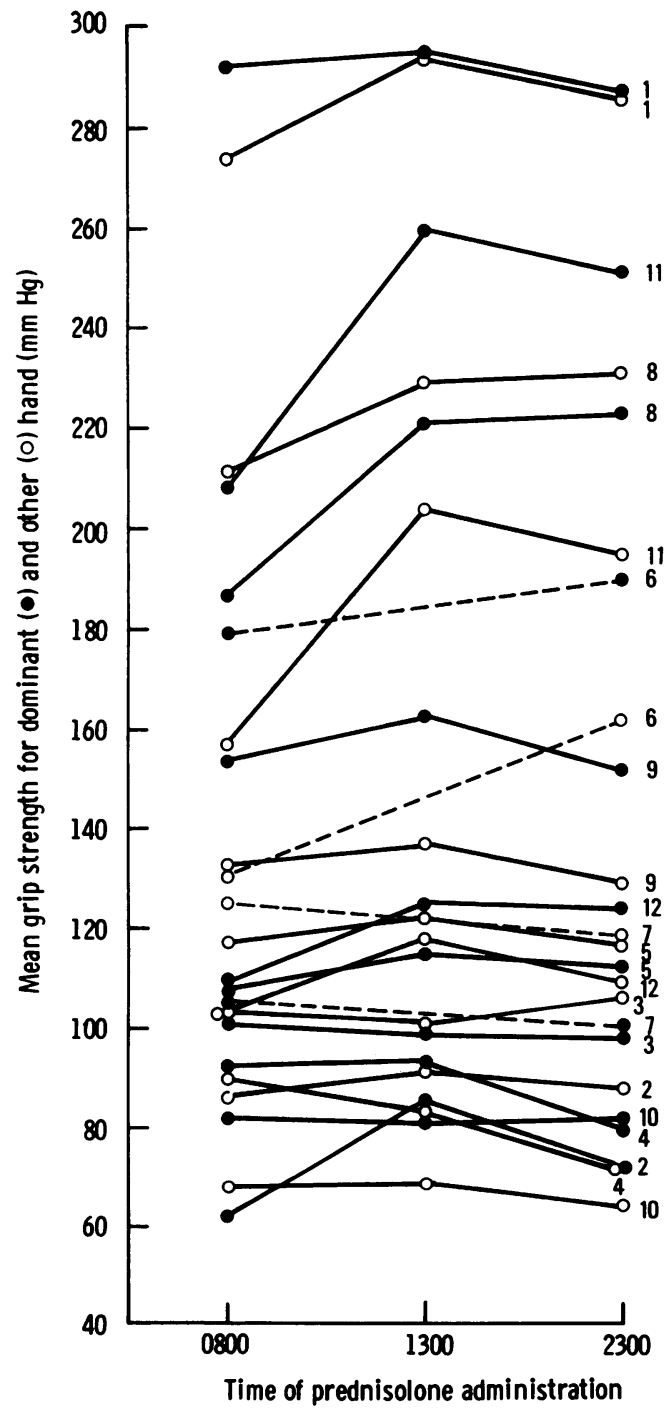

Fig. 1 Mean grip strengths for both hands of each patient on different times of prednisolone administration. Grip strengths were slightly better when prednisolone was administered at $1300 \mathrm{~h}$ (dominant hands $p<0.05$, other hand $p=0.05)$. There was no difference in grip strength between the $0800 \mathrm{~h}$ and the $2300 \mathrm{~h}$ administration times. be more severe. A controlled trial of prednisolone at different times of day was performed to assess therapeutic effectiveness and to study any alteration in urinary excretion patterns.

\section{Patients and methods}

Twelve patients with rheumatoid arthritis were studied in a double-blind trial. Details of the patients are given in Table 1.

Single daily doses of prednisolone at 3 times of day were compared: $0800 \mathrm{~h}, 1300 \mathrm{~h}$, and $2300 \mathrm{~h}$. Placebo tablets were taken at the other times. Each patient's daily dose of prednisolone remained the same throughout the trial, and only the time of its administration was changed. All other medication was taken at the same time and dosage. The patients were studied on all 3 regimens in randomised order and served as their own controls.

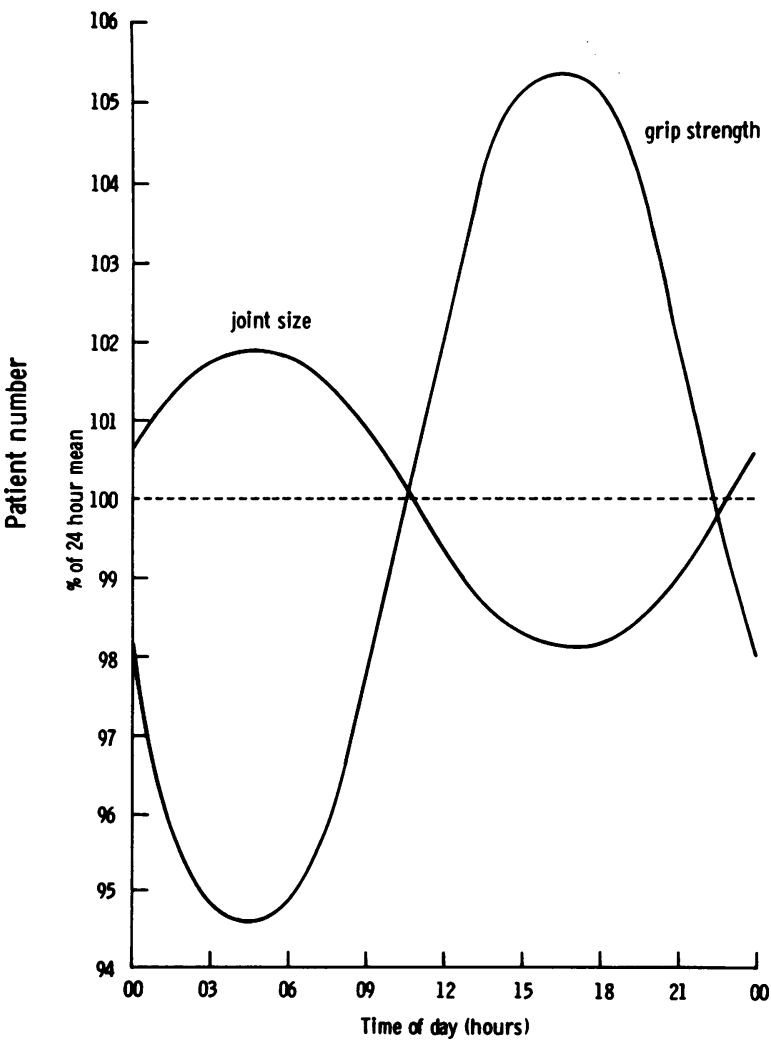

Fig. 2 Group circadian rhythms of grip strength of the dominant hand and of the sum of 10 finger joints for 12 patients taking prednisolone at $0800 \mathrm{~h}$. The data are expressed as the best fitting sine wave with a period of 24 hours. Joint swelling is maximal and grip strength is minimal at about $0500 \mathrm{~h}$. Similar patterns were observed when patients took prednisolone at $1300 \mathrm{~h}$ or at $2300 \mathrm{~h}$. 
All measurements were made by the patients at home ${ }^{7}$ to avoid the stress of hospitalisation and to collect information in the situation where the treatment is usually given. No attempt was made to control diet or activity, but patients were asked to maintain as stable a routine as possible.

For at least 3 days during the fourth week of each treatment regimen patients collected urine and made objective and subjective assessments of their arthritis. At each micturition, which was not required at a set time, patients measured the urine volume and refrigerated an aliquot. Signs and symptoms were assessed following micturition by measuring finger joint sizes, grip strength, subjective stiffness, and pain as described elsewhere. ${ }^{8}$ When necessary patients recorded the number of paracetamol tablets they took for extra analgesia.

Urine sodium, potassium, chloride, calcium, creatinine, and osmolar concentrations were determined by standard laboratory techniques. Urinary 11-hydroxycorticosteroids (11-OHCS) were analysed by a fluorimetric method. ${ }^{9}$

The trial was conducted between February 1979 and April 1980.

\section{Results}

SIGNS AND SYMPTOMS

The mean sum of 10 joints was calculated for each patient on each regimen. No significant difference in finger joint sizes due to timing of treatment was observed by Wilcoxon's paired test.

The mean grip strengths for each patient's right and left hands were calculated for each treatment regimen and are shown in Fig. 1. Prednisolone at $0800 \mathrm{~h}$ and at $2300 \mathrm{~h}$ was equally effective as assessed by grip strength. Administration at $1300 \mathrm{~h}$ was associated with stronger grip in the right hands $(p<0 \cdot 05)$. There were no differences in pain or stiffness ratings, or in the number of paracetamol tablets ingested between treatments.

Circadian variations in grip strength and finger joint sizes were investigated. Grip strength was minimal in the morning at about $0500 \mathrm{~h}$, when joint swelling was maximal. This pattern did not change with different timing of prednisolone therapy and is similar to the circadian variations observed by us in patients with rheumatoid arthritis treated with other drugs $^{8}$ and to those in normal subjects. ${ }^{10}$ Fig. 2 shows the average circadian rhythm of grip strength and joint size for patients taking prednisolone at $0800 \mathrm{~h}$, calculated by the methods of Nelson et al. ${ }^{11}$

URINARY EXCRETION PATTERNS

Using paired nonparametric tests we found no differences in the 24-hour excretion rates due to the timing of prednisolone administration for any of the urinary

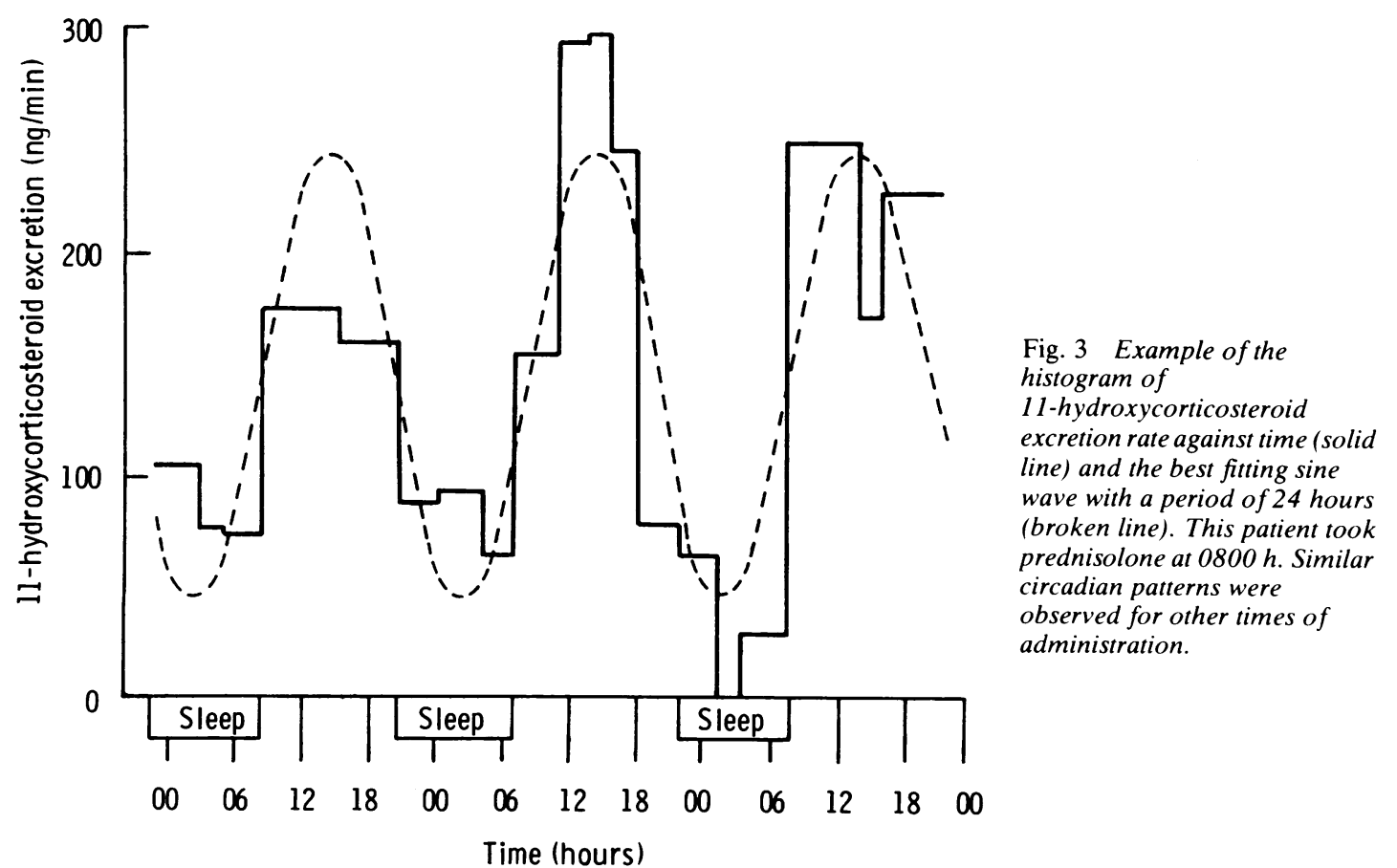

Fig. 3 Example of the istogram of excretion rate against time (solid line) and the best fitting sine wave with a period of 24 hours (broken line). This patient took prednisolone at $0800 \mathrm{~h}$. Similar circadian patterns were observed for other times of administration. 
constituents investigated, and they were all within the normal range in our laboratories. Mean 24-hour 11-OHCS excretion $( \pm$ SEM) was $192 \pm 41,161 \pm 15$ and $176 \pm 27 \mu \mathrm{g}$ for $0800 \mathrm{~h}, 1300 \mathrm{~h}$, and $2300 \mathrm{~h}$ prednisolone administration respectively. The range in untreated subjects is 80 to $380 \mu \mathrm{g}$ per 24 hours.

To examine the pattern of urinary excretion within each 24-hour period the ratio of the amount excreted during daytime activity to the amount excreted during nocturnal recumbency ( $\mathrm{D} / \mathrm{N}$ ratio) was used. No significant differences in the $D / N$ ratio between regimens were found by paired nonparametric tests for any of the urinary variables studied.

Generally about twice as much of all constituents was excreted during daytime activity as during nocturnal recumbency on all regimens. This pattern is similar to that seen in untreated controls of comparable age. ${ }^{12}$

The pattern of excretion within the day was also investigated by calculating the sine wave with a period of 24 hours that best fitted the histogram of excretion rate against time. ${ }^{13}$ An example is shown in Fig. 3. The parameters defining the best-fit sine wave were calculated for each patient on each treatment regimen, and were then used to derive group circadian rhythms of excretion. ${ }^{11}$

When prednisolone was administered at $0800 \mathrm{~h}$, group circadian rhythms of volume, potassium, sodium, chloride, and osmolar excretion rates were maximal in the afternoon. In some individuals excretion rates peaked later in the evening, or even during the night and early morning hours when prednisolone was taken at the later times of $1300 \mathrm{~h}$ and $2300 \mathrm{~h}$. But for the whole group this tendency did not reach statistical significance.

Group circadian rhythms of calcium and creatinine excretion were maximal in the afternoon on all treatment regimens. The maximal rate of excretion of 11-OHCS for the group was in the middle of the day on all treatments (Fig. 3), as it is in untreated patients. ${ }^{14}$ Individual patients varied greatly from each other, so paired comparisons were made between the best-fitted sine waves for each patient on each treatment regimen. No consistent changes attributable to the timing of steroid therapy could be discerned.

\section{Discussion}

When prescribing potentially harmful drugs a balance between side effects and therapeutic effectiveness is attempted. It has been assumed that to control the symptoms of rheumatoid arthritis at least part of a dose of prednisolone should be given in the evening ${ }^{15}$ despite this not being the most appropriate time if adrenopituitary suppression is to be prevented.
De Andrade et al. ${ }^{2}$ compared morning and evening administration of $5 \mathrm{mg}$ prednisolone and found that 23 out of 49 patients preferred the evening dose. However, $75 \%$ of these patients were accustomed to taking the drug at night for a mean of 8 months. Our observations suggest that prednisolone was equally effective when given at $0800 \mathrm{~h}, 1300 \mathrm{~h}$, or $2300 \mathrm{~h}$ and could therefore be prescribed at any of these times if this resulted in fewer side effects. Our study differs from that of De Andrade et al. in the method of assessing therapeutic effect, and also the patients in our study were taking other anti-inflammatory drugs as well as prednisolone. Combined drug therapy is more usual in clinical practice, and so our conclusions may be more relevant.

Our findings support the work of Nugent et al., ${ }^{16}$ who found that once-daily morning prednisolone was as effective as 4 smaller doses per day in 28 patients with rheumatoid arthritis who took a mean daily dose of between 7 and $16 \mathrm{mg}$. Single morning administration for diseases other than rheumatoid arthritis is also reported to be as effective as divided doses. ${ }^{17} 18$

Suppression of the adrenopituitary axis is minimised when low-dose corticosteroids are taken only in the morning to coincide with high endogenous plasma cortisol levels. ${ }^{419}$ In a morning-only regimen the normal circadian rhythm of plasma cortisol levels is preserved, whereas the literature indicates that with long-term evening doses, or with divided doses, the morning increase of endogenous corticosteroids is likely to be abolished or reduced on the next day ${ }^{20}{ }^{21}$ It follows that if corticosteroids are given at a dose level and at a time that suppresses the adrenopituitary axis, the total amount of corticosteroid available to the patient may be less than if the same dose is given at a time when suppression is reduced, because in the latter circumstances the corticosteroids produced by the patient's adrenals will be additive to the exogenous drug treatment.

The 11-OHCS excretion exhibited a circadian rhythm in the patients studied, with a peak at about midday on all 3 treatment regimens (Fig. 3). The pattern observed is similar to that seen in untreated people, ${ }^{14}$ and the total 11-OHCS excreted per 24 hours for all 3 regimens was well within the range seen in our laboratory for normal subjects. Impairment of rhythmic cortisol production was not detected in these patients, irrespective of the time of prednisolone administration. There is no reason to suppose that the urinary method used was not sufficiently sensitive to detect suppression, particularly as multiple collections were available each day rather than a single 24-hour combination, and this permits a critical evaluation of the cyclical pattern of excretion.

Klinefelter $e t$ al. ${ }^{1}$ showed that the adrenal response to stimulation with ACTH may not be impaired when 
doses of less than $15 \mathrm{mg}$ prednisolone per day are taken, even when ingested once daily at night for up to 3 years. In contrast Jasani et al. ${ }^{22}$ found that about half their patients, who took similar doses of a variety of glucocorticoid preparations, had abnormal circadian variations of plasma cortisol irrespective of the timing of treatment.

It seems that adrenal suppression is a side effect of low-dose prednisolone in some but not all patients. The 12 patients in our study did not show any signs of impaired cortisol production, and as they were all taking low doses of prednisolone this is not inconsistent with the literature.

To summarise, suppression of the adrenopituitary axis by exogenous glucocorticoids depends on the duration of therapy, the daily dosage, the time of administration, the molecular structure, and the formulation of the steroid used. ${ }^{23}$ Many publications do not provide this information, making comparison of studies difficult.

Nocturia is sometimes a side effect of steroid therapy. ${ }^{5}$ Patients who have constantly high circulating cortisol levels due to Cushing's syndrome excrete more water and electrolytes at night than in the day, ${ }^{24}$ and this disturbed excretory pattern was reproduced by Imrie et al. ${ }^{25}$ who administered $5 \mathrm{mg}$. of prednisolone 5 times a day to healthy subjects.

Reindl et al. ${ }^{26}$ found that potassium and chloride excretion rates peaked as much as 10 hours later when prednisolone was given in the evening to children with asthma. Dose levels were not specified by the authors. In a pilot study of the effect of the time of prednisolone administration on urinary excretion patterns we found that prednisolone at $2300 \mathrm{~h}$ was associated with decreased amplitude and delayed peak excretion of sodium, potassium, and total solutes compared with $0800 \mathrm{~h}$ administration.${ }^{27}$ In some patients with small bladder capacities the shift of excretion to the night hours resulted in nocturia. The patients studied in this trial did not get this troublesome symptom, though there was a trend for the time of the peak of urinary electrolyte excretion to be later when prednisolone was taken at $2300 \mathrm{~h}$.

Adrenal and renal rhythms may be linked, particularly the rhythm of circulating cortisol with the excretory rhythms of potassium. ${ }^{28}$ On the basis of 11-OHCS excretion the patients in this study had normal adrenal cortical function. Their urinary electrolyte excretion patterns were similar to those reported from healthy subjects. ${ }^{1429}$

It may be concluded that in many patients a single morning dose of prednisolone will be as effective as the same dose taken at other times of day. Side effects were not seen in this study with evening doses, but it would seem appropriate to prescribe the drug once a day in the morning initially, as the integrity of the hypothalamic-pituitary-adrenal axis will be better preserved. Patients may be less at risk from other side effects but will have symptoms adequately controlled. The dose reduction and withdrawal of corticosteroid may be easier to achieve with regimens that ensure adrenopituitary function during steroid therapy.

This study was carried out with financial assistance from the Nottingham and Notts Kidney Fund, the Boots Company Ltd, and the Medical Research Council. Prednisolone and placebo tablets were donated by Pfizer Ltd. Julia Mackenzie performed the computer analyses and Judith Hayes typed the manuscript. Thanks are due especially to the patients, who all made many collections and measurements.

\section{References}

${ }^{1}$ Klinefelter H F, Winkenwerder W L, Bledsoe T. Single daily dose prednisolone therapy. JAMA 1979; 241: 2721-33.

2 De Andrade J R, McCormick J N, Hill A G S. Small doses of prednisolone in the management of rheumatoid arthritis. Ann Rheum Dis 1964; 23: 158-62.

${ }^{3}$ Bolt H M. Prinzipien der zirkadianen und alternierenden Therapie mit Kortikosteroiden und Einfluss auf das Hypophysen-Nebennierenrinden-System. Allergologie 1980; 3: $171-6$.

4 Nichols T, Nugent C A, Tyler F H. Diurnal variations in suppression of adrenal function by glucocorticoids. J Clin Endocrinol 1965; 25: 343-9.

5 Thomas J P, Coles G A, El-Shaboury A H. Nocturia in patients on long-term steroid therapy. Clin Sci 1970; 38: 415-25.

6 Kowanko I C, Readett D, Pownall R, Swannell A J, Mahoney P, Knapp M S. Nocturia, a side-effect of single dose prednisolone and its dependence on the time of day of taking steroid. Chronobiologia 1978; 5: 181-2.

${ }^{7}$ Hillier P, Knapp M S. The domiciliary measurement of human physiological rhythms. J Physiol 1974; 242: 45-6.

- Kowanko I C, Pownall R, Knapp M S, Swannell A J, Mahoney P G C. Circadian variations in the signs and symptoms of rheumatoid arthritis and in the therapeutic effectiveness of flurbiprofen at different times of day. Br J Clin Pharmacol 1981; 11: 477-84.

9 Mattingley D. A simple fluorimetric method for the evaluation of free 11-hydroxycorticoids in human plasma. J Clin Pathol 1962; 15: 374-9.

${ }^{10}$ Ilmarinen $\mathrm{J}$, Ilmarinen $\mathrm{R}$, Korhonen $\mathrm{O}$, Nurminen $\mathrm{M}$. Circadian variation of physiological functions related to physical work capacity. Scand J Work Environ Health 1980; 6: 112-22.

1 Nelson W, Tong Y L, Lee J K, Halberg F. Methods for cosinor-rhythmometry. Chronobiologia 1979; 6: 305-23.

12 Hillier P, Knapp M S. Circadian variations in urine excretion in chronic renal failure. $Q J$ Med 1980; 49: 461-78.

${ }^{13}$ Fort A, Mills J N. Fitting sine waves to twenty-four hour urinary data. Nature 1970; 226: 657-8.

14 Bartter F C, Delea C S, Halberg F. A map of blood and urinary changes related to circadian variations in adrenal cortical function in normal subjects. Ann NY Acad Sci 1962; 98: 969-83.

1s Murthy M H V, Rhymer A R, Wright V. Indomethacin or prednisolone at night in rheumatoid arthritis. Rheumatol Rehabil 1978; 17: 8-13.

${ }_{16}$ Nugent C A, Ward J, MacDiarmid W D, McCall J C, Baukol J C, Tyler F H. Glucocorticoid toxicity. Single contrasted with divided daily doses of prednisolone.J Chronic Dis 1965; 18: 323-32.

${ }_{17}$ Myles A B, Bacon P A, Daly J R. Single daily dose

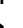


corticosteroid treatment. Effect on adrenal function and therapeutic efficacy in various diseases. Ann Rheum Dis 1971; 30: $149-53$.

${ }^{18}$ Powell-Tuck J, Bown R L, Lennard-Jones J E. A comparison of oral prednisolone given as single or multiple daily doses for active protocolitis. Scand J Gastroenterol 1978; 13: 833-7.

19 Myles A B, Schiller L F G, Glass D, Daly J R. Single daily dose corticosteroid treatment. Ann Rheum Dis 1976; 35: 73-6.

${ }^{20}$ DiRaimondo V C, Forsham P H. Some clinical implications of the spontaneous diurnal variation in adrenal cortical secretory activity. Am J Med 1956; 21: 321-3.

${ }^{21}$ Segre E J, Klaiber E L. Therapeutic utilization of the diurnal variation in pituitary-adrenocortical activity. Californ Med 1966; 104: 363-5.

22 Jasani M K, Diver M J, Bell A M, Dalakos T G, Buchanan W W. Some clinical observations on the diurnal rhythm of plasma cortisol (11-OHCS) in patients with rheumatoid arthritis treated with oral corticosteroid drugs. Curr Med Res Opin 1974; 2: 373-86.

${ }^{23}$ Voigt K H, Fehm H L. Die normale Regulation der Hypothamus-Hypophysen-Nebennieren-Achse. Allergologie 1980; 3: 158-63.

${ }^{24}$ Doe R P, Vennes J A, Flink E B. Diurnal variation of 17-hydroxycorticosteroids, sodium, potassium, magnesium and creatinine in normal subjects and in cases of treated adrenal insufficiency and Cushing's syndrome. J Clin Endocrinol Metab 1960; 20: 253-65.

${ }^{25}$ Imrie $\mathbf{M} \mathbf{J}$, Mills $\mathbf{J} \mathbf{N}$, Williamson $\mathrm{K}$ S. Circadian variations in renal and adrenal function: Are they connected? Mem Soc Endocrinol 1963; 13: 3-8.

${ }^{26}$ Reindl K, Falliers C, Halberg F, Chai H, Hillman D, Nelson W. Circadian acrophase in peak expiratory flow rate and urinary electrolyte excretion of asthmatic children: phase shifting of rhythms by prednisolone given in different circadian system phases. Rass Neurol Veg 1969; 23: 5-26.

${ }^{27}$ Kowanko I C, Pownall R, Swannell A J, Mahoney P G C, Knapp M S. The effect of timing of prednisolone therapy on circadian patterns of urinary excretion. Chronobiologia 1979; 6: 121.

${ }^{28}$ Moore-Ede M C, Schmelzer W S, Kass D A, Herd J A. Cortisol-mediated synchronization of circadian rhythm in urinary potassium excretion. Am J Physiol 1977; 233: R230-R238.

${ }^{29}$ Minors D S, Mills J N, Waterhouse J M. The circadian variations of the rates of excretion of urinary electrolytes and of deep body temperature. Int J Chronobiol 1976; 4: 1-28. 